\title{
Modeling and Simulation of a Chip Load Acting on a Single Milling Tool Insert
}

\author{
Virginija Gylienè ${ }^{1, *}$ - Vytautas Ostaševičius ${ }^{1}$ \\ 1 Kaunas University of Technology, Faculty of Mechanical Engineering and Mechatronics, \\ Department of Engineering Design, Lithuania
}

The paper presents experimental and numerical study of the end-milling process. The aim of this study is to define the force acting on a single cutting tool insert. It was accomplished by transforming cutting force signals from coordinate system of Kistler dynamometer into milling tool coordinate system.

In addition, a finite element model of the milling process was composed by adopting the hypothesis of the cut cross-section. Finally, finite element simulations were performed in order to determine the residual stress distribution across the depth of the machined surface.

Keywords: finite element (FE) modeling, end-milling, cross-cut section

\section{INTRODUCTION}

Metal removal is a key technology in the aerospace and automotive manufacturing sectors, where the demand for high productivity and high accuracy is steadily increasing [1].

A large number of theoretical and experimental studies on surface profile and roughness of machined products have been reported. These studies show that cutting conditions, tool wear, the material properties of tool and workpiece, as well as cutting/process parameters significantly influence the surface finish of machined parts [2]. Geometrical deviations with respect to the nominal surface are associated with the changes in component shape, periodical surface irregularities and structural modifications. Residual stresses are considered as the fifth- and sixth-order deviations and are attributed to the physicochemical factors that influence the structural changes of the surface [2]. However, component processing by cutting induces stress gradients in the structure, which may have either a positive or negative effect on the component [3] and [4]. It is common that the residual stresses accompanied by the fatigue arising due to cyclic loading lead to the unexpected component fracture [4], while compressive stresses generated as a result of cutting operations are usually beneficial [5].

Therefore, it is of particular importance to consider residual stresses in those mechanical components that operate under conditions characterized by fatigue loading, e.g. parts in power stations, structures in aviation, etc. ([3] and [4]). Evaluation of residual stresses is performed by taking into account the type of tested material, while specific characterization methods are selected based on a particular type of the residual stress ([4] and [6] to [8]). The need for evaluation of residual stresses is associated with extensive application of numerical techniques based on the finite element (FE) method ([7] and [9] to [13]).

The influence of a cutting process on the formation of residual stresses is ambiguous. Increase of the residual stresses is related with the majority of machining parameters including cutting speed, depth of cut and tool edge radius [12]. However, the layer of removed material has the greatest effect on the formation of the residual stresses. Authors [5] defined that the superficial residual stresses at the surface slightly decreased when the rake angle increased from -5 to $5^{\circ}$. This decrease on superficial residual stresses with the rake angle was accomplished with a reduction of the thickness of the tensile layer [5] and [12]. On the other hand, when the uncoated tool was replaced by a coated one, the superficial residual tensile stresses increase by $240 \mathrm{MPa}$, when the highest cutting speed value was used [12].

Thus, numerical analysis is an attractive alternative for evaluating residual stresses allowing to substitute the application of high-cost experimental methods. On the other hand, some of the computational results do not correlate with the experimental findings [7].

In summary, despite the fact that there exists a large variety of different analytical, numerical and experimental techniques, currently there is no proven analytical model enabling to reliably predict the residual stresses that arise in the course of cutting operations [7].

For ensuring reliability of the developed FE model it must be verified against experimental data which includes magnitudes of the measured cutting force. Cutting force is a parameter which is also evaluated for the structural design of machine tools, selection of optimum cutting parameters, design 
of workpiece-holding fixtures, tool stress analysis, spindle bearing design, and the real time monitoring of tool wear and breakage [14].

This study proposes a FE model for a case of the milling process. The milling operation is performed by using end-milling tool - a cutting tool of complex geometry that is used for machining of curvilinear surfaces. Therefore, a FE model was constructed for performing mesoscopic analysis of the milling process in terms of the removed material cut cross-section.

Cutting forces were evaluated during experimental testing, while the effect of the cutting force on a single cutting insert was determined by means of a transformation matrix.

Furthermore, it was confirmed with respect to material deformation that it is necessary to apply several criteria for verification of the FE model [15].

Therefore, numerical analysis was carried out by using dynamic material characteristics taken from the available literature sources [16], meanwhile dynamic material deformation constants were acquired from the performed turning experiments [15].

\section{EXPERIMENTAL SETUP FOR END-MILLING}

End milling (or partial face milling) experiments were performed on a universal milling machine Dufour-164 (3-axis). Force measurement was executed using a 3-component piezoelectric force sensor - Kistler dynamometer 9257A. Workpiece material was steel AISI 1034 (or Afnor standard XC38). Cutter was $25 \mathrm{~mm}$ diameter with two uncoated carbide inserts (APKT 1604 PD ER-43 from Stellram). No cutting fluids were used. Milling experiments were performed with the medium carbon steel. Its chemical composition and mechanical properties are presented in Table 1. Milling conditions are presented in Table 2.
Force measurements were performed according to cutting depth. In this paper, analysis will be performed only with respect to cutting depth. Scheme of experiments is presented in Fig. 1.

Workpiece was mounted on Kistler dynamometer, longitudinal cutting force was in axis $Y$, and transversal cutting force was in axis $X$. Equipment calibration was performed, using tension - compression setup Instron 5569.

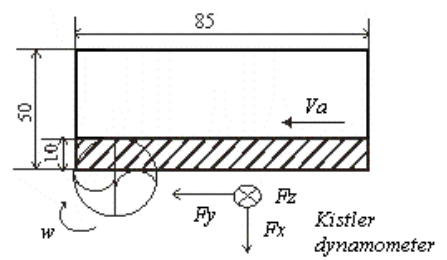

Fig. 1. Milling experimental scheme from top

Dynamometer signal curves allowed to characterize a cutting process. It was observed that the influence of the cutting forces onto the cutter tooth is stable.

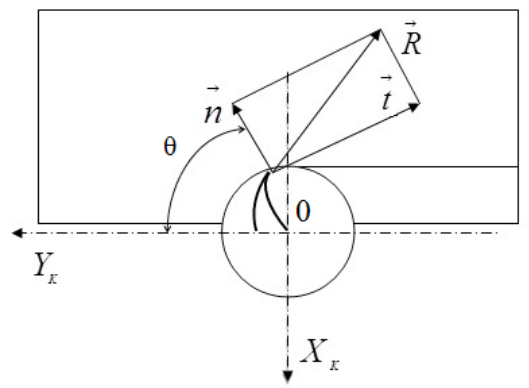

Fig. 2. Milling tool position evaluation according to Kistler dynamometer coordinate system

In order to define the real influence on the cutting tool insert, the transfer of the measured forces from

Table 1. Chemical and mechanical properties of AISI 1034 steel

a) Chemical composition of AISI 1034 steel (\% weight)

\begin{tabular}{cccccc}
\hline C & Fe & Mn & P & S & Cr \\
\hline 0.32 to 0.38 & 98.73 to 99.18 & 0.50 to 0.80 & $\leq 0.04$ & $\leq 0.05$ & $\leq 0.25$ \\
\hline b) Mechanical properties of AISI 1034 steel & & & & \\
\hline \multicolumn{2}{l}{ Density $\left[\times 1000 \mathrm{~kg} / \mathrm{m}^{3}\right]$} & Elastic modulus $[\mathrm{GPa}]$ & Strength limit $[\mathrm{MPa}]$ & Failure strain & Hardness HRC \\
\hline 7.8 & 200 & 698 & 0.72 & 35 \\
\hline
\end{tabular}

Table 2. Cutting conditions

\begin{tabular}{cccccc}
\hline $\begin{array}{c}\text { Cutting speed [m/min] } \\
\text { (calculated) }\end{array}$ & $\begin{array}{c}\text { Spindle speed } \\
{[\mathrm{rev} / \mathrm{min}]}\end{array}$ & $\begin{array}{c}\text { Feed } \\
{[\mathrm{mm} / \mathrm{th}]}\end{array}$ & $\begin{array}{c}\text { Feed rate } \\
{[\mathrm{mm} / \mathrm{min}]}\end{array}$ & $\begin{array}{c}\text { Width of cut } \\
{[\mathrm{mm}]}\end{array}$ & $\begin{array}{c}\text { Depth of cut } \\
{[\mathrm{mm}]}\end{array}$ \\
\hline 118 & 1500 & 0.1 & 310 & 10 & $0.5 ; 0.75 ; 1.0$ \\
\hline
\end{tabular}


dynamometer coordinate system into the tool system was executed.

Cutting force measurements were performed in the coordinate system of the dynamometer $R_{\mathrm{K}}\left(0, X_{K}\right.$, $\left.Y_{K}, Z_{K}\right)$. Fig. 2 presents the explication scheme of the cutting tool coordinate system according to the Kistler dynamometer coordinate system.

In order to define the measured cutting force by dynamometer, the coordinate system transfer is expressed:

$$
P=\left[\begin{array}{ccc}
-\cos \theta & -\sin \theta & 0 \\
\sin \theta & -\cos \theta & 0 \\
0 & 0 & 1
\end{array}\right] .
$$

The transfer of coordinate system is expressed:

$$
\left[X_{\text {tool }}\right]=\left[P^{-1}\right] \times\left[X_{K}\right] .
$$

Finally, the total measured force is expressed in the tool coordinate system:

$$
R_{\text {tool }} \mid \begin{gathered}
\vec{n}=-\cos \theta \cdot \overrightarrow{X_{K}}+\sin \theta \cdot \overrightarrow{Y_{K}} \\
\vec{t}=-\cos \theta \cdot \overrightarrow{Y_{K}}-\sin \theta \cdot \overrightarrow{X_{K}}, \\
Z_{\text {tool }}=Z_{K}
\end{gathered}
$$

where $\theta$ is an edge engagement angle $\left[^{\circ}\right]$.

The total cutting tool force in the horizontal plane was evaluated:

$$
R^{2}=F_{x K}^{2}+F_{y K}^{2},
$$

where $F_{x K}, F_{y K}$ are cutting forces measured by Kistler dynamometer in [V] $X, Y$ plane workpiece system.

Only one milling tool insert was performing a cutting action at a time. Therefore, the force load onto a single cutting insert was estimated.
Transformation of the coordinate system enables establishment of the magnitude of a cutting force acting on a single tooth of the mill cutter. Fig. 3 provides measured longitudinal ( $Y$ direction) and transverse ( $X$ direction) resultant force variations in time according to Eq. (4). Fig. 3 indicates that the duration of cutting pass of a single mill tooth is approximately $0.01 \mathrm{~s}$.

According to Eq. (3), Fig. 4 provides tangential and normal forces acting on the cutter tooth. Forces acting on a single mill tooth, which were measured and subsequently recalculated, are not equal because of possible differences in the mounting of inserts.

In the case of end milling, forces $\vec{F}_{t}$ and $\vec{F}_{n}$ are equal to zero from $\theta=0$ and acquire maximum values at $\theta=\pi-\arccos \left(1-\frac{2 \times a_{e}}{D}\right)$, where $D$ is the diameter of the cutting tool [mm] and $a_{e}$ width of cut. Finally, the forces diminish to zero upon tooth retraction from the material when $\theta=\pi$.

As mentioned above, the $25 \mathrm{~mm}$ diameter tool cuts the width of cut of $10 \mathrm{~mm}$. Therefore, in Fig. 4, it is observed that the cutting insert is not removing the material, while tool rotates $1.7 \mathrm{rad}$.

It is also observed from Fig. 4 that cutting force $F_{t}$ when it reaches maximum cross-section of the chip is about $180 \mathrm{~N}$. Normal cutting force $F_{n}$ is about 145 $\mathrm{N}$ (variation between 130 and $160 \mathrm{~N}$ ). For further FE analysis the average of cutting forces will be taken.

\section{NUMERICAL STUDY OF MILLING PROCESS}

\subsection{Evaluation of Dynamic Behavior Law}

FE numerical software ANSYS as pre-processor and LS-DYNA as post-processor were used to compose FE geometrical model of the milling process and

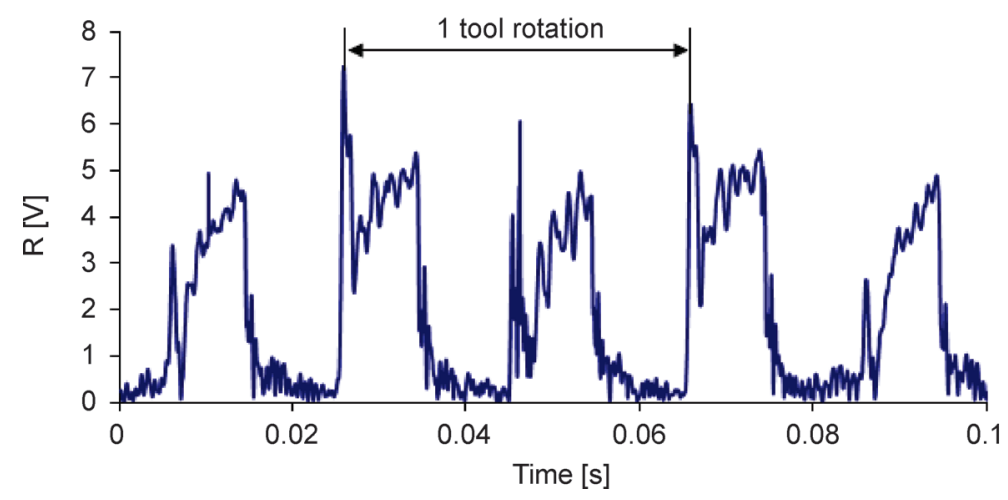

Fig. 3. Total force action on a single cutting tool insert (cutting depth $=0.5 \mathrm{~mm}$ ) 


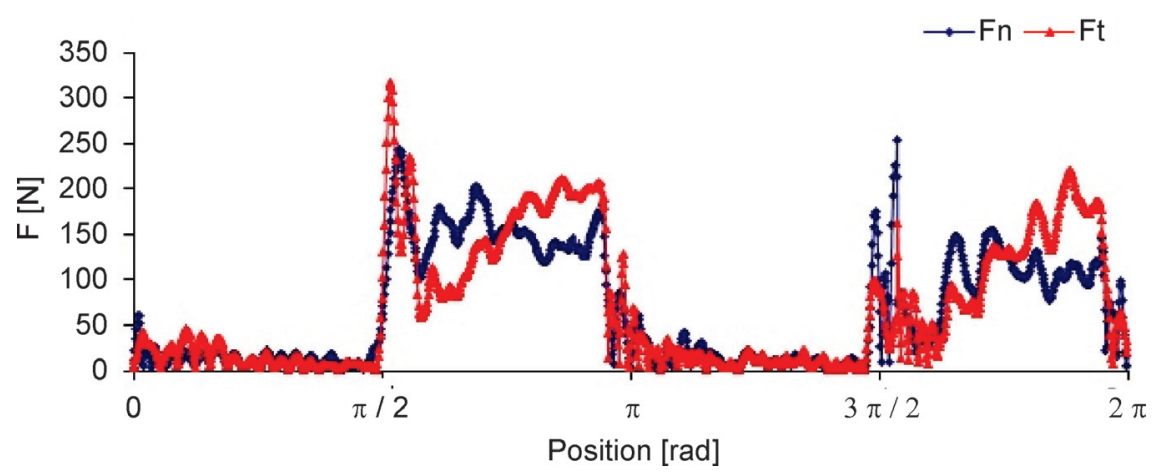

Fig. 4. Tangential $F_{t}$ and radial $F_{n}$ force action onto a two milling inserts, during one milling tool rotation (cutting depth=0.5 $\mathrm{mm}$ )

define dynamic behavior of material subjected to cutting.

The classic tension experiments were performed to determine actual material characteristics, which are presented in Table 1. The obtained stress-strain relationship allowed to determine tangential modulus of elasticity; $E_{t}=582.6 \mathrm{MPa}$.

Dynamic effects of strain rates are taken into account by scaling static yield stress with the factor, assumed by Cowper - Symonds relation [16]:

$$
\sigma_{y}=\left[1+\left(\frac{\dot{\varepsilon}}{C}\right)^{\frac{1}{P}}\right]\left(\sigma_{y}+\beta E_{p} \varepsilon_{e f f}^{p}\right),
$$

where $\dot{\varepsilon}=\sqrt{\dot{\varepsilon}_{i j} \dot{\varepsilon}_{i j}}$ is a strain rate, and $C, P$ constants of Cowper - Symonds relation.

The current radius of the yield surface, $\sigma_{y}$ is the sum of the initial yield strength, $\sigma_{0}$ plus the growth $\beta E_{p} \varepsilon_{e f f}^{p}$, where $E_{p}$ is the plastic hardening modulus:

$$
E_{p}=\frac{E_{t} E}{E-E_{t}},
$$

where $E_{t}$ is tangent modulus.

On the basis of the presented relation in Eq. (5), it is obvious that static and dynamic yield stress ratio depends on deformation speed. Isotropic, kinematic, or a combination of isotropic and kinematic hardening may be obtained by varying a parameter, called $\beta$ between 0 and 1 [16].

Cowper-Symonds material deformation model is frequently used to perform simulations of dynamic processes by means of FE method.

Although the majority of material constants are determined by using a classical tension test, the largest problem is associated with determination of CowperSymonds constants $C, P$. The values of constants for the steel are taken as follows: $C=40 \mathrm{~s}^{-1}, P=5$ [16].
The authors in the report [17] established the values of Cowper-Symonds constants at different deformation rates. Relative error of ca. $20 \%$ is obtained between the measured cutting force and its numerical value, which was calculated by applying dynamic constants provided in LS-DYNA library [18]. The cutting force, which was evaluated on the basis of constants obtained in [17] $\left(C=802 \mathrm{~s}^{-1}, \mathrm{P}=\right.$ $3.585)$ and taking into account the average chip crosssection [19], is smaller by $10 \%$ [20]. The experiment for the turning process was carried out by machining a workpiece of the same material by applying cutting speed that was comparable in magnitude with that of the milling process ([15] and [20]). Therefore, further numerical analysis was performed by using the following constants: $C=220 \mathrm{~s}^{-1}, \mathrm{P}=5$. The influence of material strengthening coefficients on cutting force fluctuations and residual stresses was determined.

Failure strain was another parameter to define, which initiate the chip separation from workpiece in numerical calculation. Some authors claim that the magnitude of the fracture strain does not affect simulation results [21]. Thus, taking into consideration that in the course of the cutting process the material was subjected both to temperature effect and influences arising from high deformation rate, the actual failure strain value may be 1.16 to 1.75 times larger than its static equivalent [22]. For further FE analysis the value of 1.16 was considered. The friction coefficient was assumed to be 0.5 .

\subsection{Finite Element Modeling}

The milling process FE model was composed taking in account the Hulle theory and the following aspects:

1) the tool cuts by single cutting point, which removes the straight cross-section;

2) the direction of cutting force is perpendicular to cutting edge. 
Using ANSYS as pre-processor geometrical FE model was created, assuming rake angle $\left(0^{\circ}\right)$, clearance angle $\left(11^{\circ}\right)$, and edge radius $20 \mu \mathrm{m}$. Fig. 5 illustrates the composed FE model. Boundary conditions of the FE model were as follows. The workpiece was constrained in all 6 DOFs. Load of type $U=f(t)$ (displacement according to time) was imposed on the tool with the purpose to simulate cutting motion with respect to cutting velocity.

The dimensions of workpiece were $2 \times 0.2 \times 0.75$ $\mathrm{mm}$. FE tool model was constrained using 'Swap' application. Geometric FE model contained 44112 nodes and 38512 elements.

SOLID164 elements were chosen, as they are used in explicit analysis, assuming large deformation speed and nonlinear contact. For composition of the geometric model, workpiece mesh size sensitivity study was performed [18]. The size of FE used to model workpiece was set to $0.02 \mathrm{~mm}$. The size of FE was established after definition by modeling of force stability, as presented in [18]. This FE size influences time step, so mass scaling was adjusted to be $-1.6 \mathrm{e}^{-9}$ in order to reduce CPU time. A Lagrangian explicit analysis was performed. In LS-DYNA contact interaction between two bodies was formulated using "master-slave" methodology and penalty method. For selection and specification dynamic constants by FEM the problem is interaction of deformable body - rigid body. Deformable body is workpiece and defined as "slave" for contact search and chip separation in numerical analysis. A milling tool is a rigid body, assuming tool dynamics and defined as a "master" for contact search in explicit numerical analysis.

\section{FE MODELING RESULTS}

Analysis of isotropic, kinematic or a combination of both hardening models was performed in order to define their influence on residual stress and cutting force (tangential cutting force). This material hardening aspect was performed by defining parameter $\beta$ (0 for kinematic, 1 for isotropic hardening). Fig. 6 presents calculated chip formation by FE method in time of $0.15 \mathrm{~ms}$ (time, when cutting forces are regular). It is evident that material hardening coefficient does not affect the shape of chip in material removing. In addition to the variation of hardening coefficient in the range of 0.2 to 0.8 increase of cutting force up to 50 $\mathrm{N}$ is observed, (Fig. 7). Cutting force, calculated with $\beta=0.2$ is $150 \mathrm{~N}(16 \%$ difference with experimental results). Cutting force, calculated with $\beta=0.5$ is 175 $\mathrm{N}$ (3\% difference with experimental results). Cutting force, calculated with $\beta=0.8$ is $200 \mathrm{~N}$ ( $11 \%$ difference

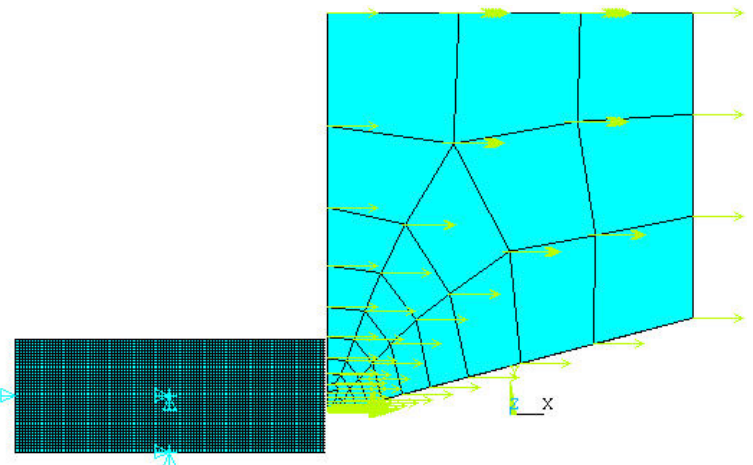

Fig. 5. FE model of milling process with removable cross-section geometric parameters

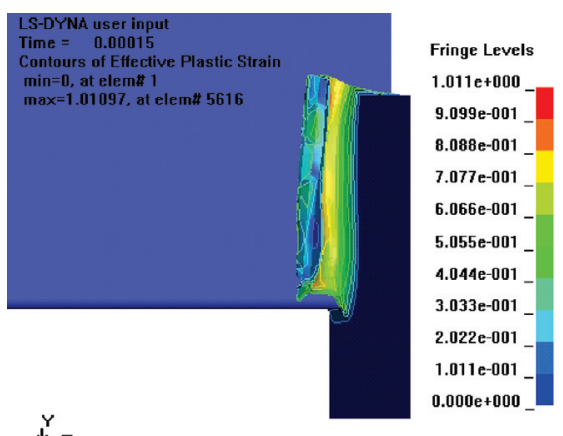

a) $\beta=0.2$

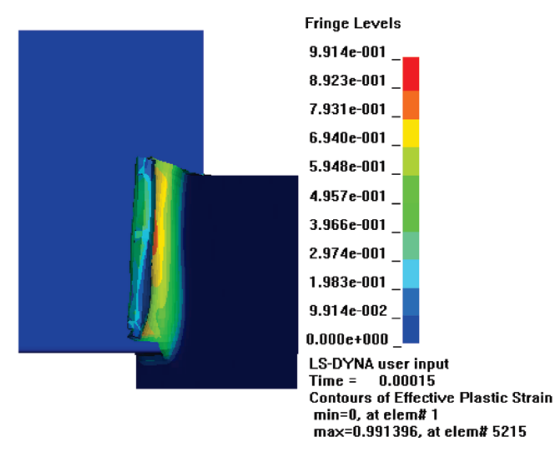

b) $\beta=0.5$

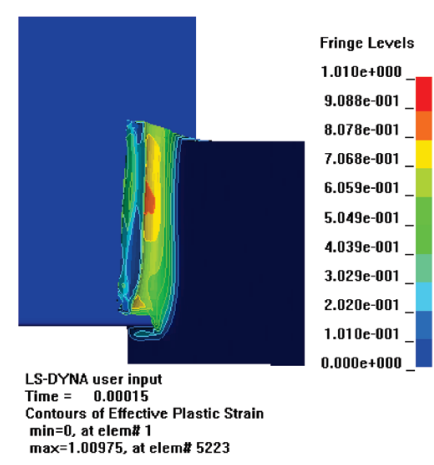

c) $\beta=0.8$

Fig. 6. Chip formation according to material hardening in milling process, after cutting force stabilization 


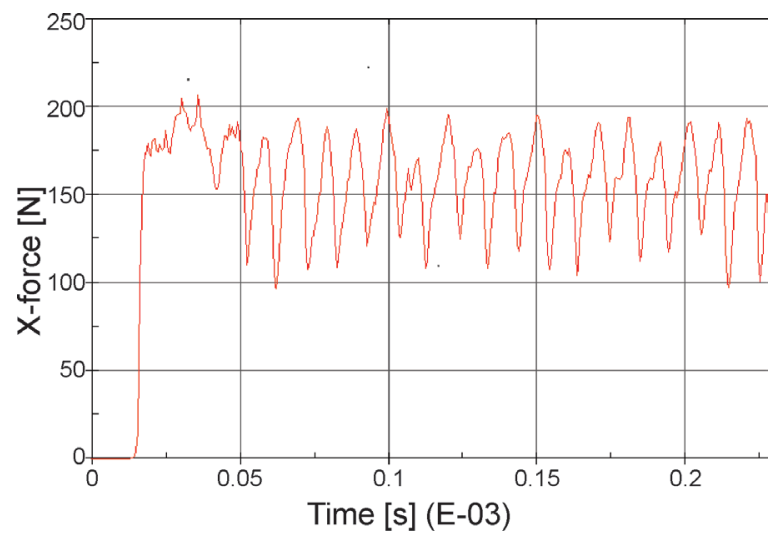

b) $\beta=0.2$

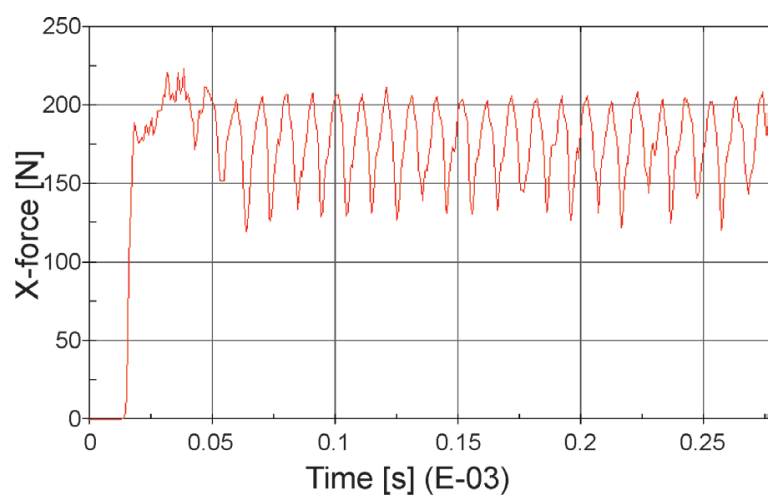

a) $\beta=0.5$

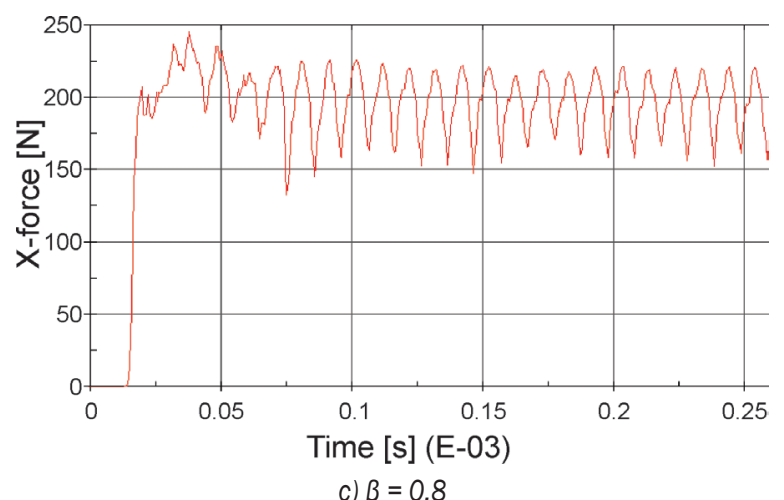

Fig. 7. Calculated cutting force (tangential cutting force)

with experimental results). Elastic-plastic behavior with kinematic and isotropic hardening artificially increases material yield point. On the other hand, when forming a FE model by taking into account material strengthening it is possible to obtain either discontinuous, segmented or continuous chip (under particular deformation rate). It is observed that this significantly influences the variation of the cutting force.
Fig. 7 also presents cutting force fluctuations. Numerically, these vibrations correspond to element deletion after reaching defined failure strain. Physically these fluctuations correspond to chip separation from the material. For this reason it was proven to introduce not only cutting force estimation but also chip form [15] in order to validate $\mathrm{FE}$ analysis.

Numerical analysis of residual stresses was performed in the same distance (and in the longitudinal direction $(X)$ ) from the edge of the workpiece.

This analysis demonstrated that on the surface of machined layer tensile stress varies in the range of 300 $\mathrm{MPa}$ according to hardening coefficient. In addition, analysis revealed high compression stresses (close to $-800 \mathrm{MPa}$ ) with material hardening coefficient $\beta=0.8$. And in all cases of work hardening the maximum of stresses was obtained at depth of 0.04 $\mathrm{mm}$. In all cases the stabilized zone according to longitudinal stresses is at the distance of $0.1 \mathrm{~mm}$.

It should be noted that these surface stresses are evaluated by taking into account contact interaction, friction, material deformation rate as well as material strengthening. However, Cowper-Symonds material deformation model does not account for thermal effects.

Calculated residual stresses without temperature effect should be compared both with experimentally determined residual stresses as well as simulation results that take into consideration thermal effects.

The main application of the developed FE model is in the field of high-speed machining (HSM) processes. During these processes the residual stresses in the workpiece are formed due to tertiary deformation zone (contact interaction, friction are predominant factors). While only $17 \%$ of primary heat zone flows into the workpiece [23].

\section{CONCLUSIONS}

This paper reports the results of investigation of cutting forces that act on a single cutting tooth during milling process. Cutting force measurements were performed in the coordinate system of the Kistler dynamometer therefore a transformation matrix was applied in order to determine cutting forces acting on a single insert within the tool coordinate system.

Experimental results indicate that cutting forces are stable during the milling process. However, forces acting on a single mill tooth (which were obtained through the application of the transformation matrix) undergo fluctuations, which may be attributed to the 
different insert mounting conditions. Although the experiment was repeated four times, the expected effect of tool wear-out is discarded here because in this case it is unlikely: tool material used in experiments was a hard-metal [24], while the feedrate was comparatively low $(0.1 \mathrm{~mm} /$ tooth $)$.

The FE model for the milling process was developed by assuming the hypothesis of the removed cut cross-section. The tool was imposed with rectilinear motion. The presented simulation results are the continuation of earlier research work, which was concerned with the evaluation of the influence of material dynamic constants and fracture deformations on the process of chip formation. Selection of appropriate dynamic constants is a tedious and timeconsuming procedure, which requires specialized experimental investigations. On the other hand, the latter aspect is responsible for the increasingly widespread adoption of the approach based on the application of turning experiments as an attractive alternative for the testing procedures that are used to evaluate dynamic material constants. Numerical results obtained with the developed model, which uses material constants determined from Fig. 7 match experimental findings very well with an error of 3\%. Obtained numerical results correspond well to the measurements.

Numerical analysis enabled prediction of distribution of machining-induced residual stresses across the depth of the workpiece surface: maximal stress values are observed at $0.04 \mathrm{~mm}$ and they vanish at a distance of $0.1 \mathrm{~mm}$ from the surface.

Future research work will be targeted towards further verification of the developed models by comparing them with the Johson-Cook constitutive model for work material behavior and application of FE modeling in ultrasonically assisted manufacturing process [25] and [26].

\section{ACKNOWLEDGEMENTS}

This research was funded by a grant (No MIP113/2010) from the Research Council of Lithuania.

\section{REFERENCES}

[1] Shi, B., Attia, H. (2010). Current status and future direction in the numerical modeling and simulation of machining processes: A critical literature review. Machining Science and Technology, vol. 14, no. 2 p. 149-188, DOI:10.1080/10910344.2010.503455.

[2] Chen, L. (2008). Study on prediction of surface quality in machining process. Journal of Materials
Processing Technology, vol. 205, no. 1-3, p. 439-450, DOI:10.1016/j.jmatprotec.2007.11.270.

[3] Le Calvez, C. (1995). Thermal and Metallurgical Aspects of Carbone Steel Orthogonal Cutting. $\mathrm{PhD}$ Thesis. Ensam, Paris. (in French)

[4] Withers, P.J., Bhadeshia, H.K.D.H. (2001). Residual stress. Part 1 - Measurement techniques. Materials Science and Technology, vol. 17, no. 4, p. 355-365, DOI:10.1179/026708301101509980.

[5] Outeiro, J.C., Dias, A.M., Jawahir, I.S., (2006). On the effects of residual stresses induced by coated and uncoated cutting tools with finite edge radii in turning operations. CIRP Annals - Manufacturing Technology, vol. 55, no. 1, p. 111-116, DOI:10.1016/S00078506(07)60378-3.

[6] Withers, P.J., Bhadeshia, H.K.D.H. (2001). Residual stress. Part 2 - Nature and origins. Materials Science and Technology, vol. 17, no. 4, p. 366-375, DOI:10.1038/35070640.

[7] Jawahir, I.S., Brinksmeier, E., M'Saoubi, R., Aspinwall, D.K., Outeiro, J.C., Meyer, D., Umbrello, D., Jayal, A.D. (2011). Surface integrity in material removal processes: Recent advances. CIRP Annals Manufacturing Technology, vol. 60, no. 2, p. 603-626, DOI:10.1016/j.cirp.2011.05.002.

[8] Mittal, S., Liu, C.R., (1998). A method of modeling residual stresses in superfinish hard turning. Wear, vol. 218, no. 1, p. 21-33, DOI:10.1016/S00431648(98)00201-4.

[9] Schulze, V., Autenrieth, H., Deuchert M., Weule, H. (2010). Investigation of surface near residual stress states after micro-cutting by finite element simulation. CIRP Annals - Manufacturing Technology, vol. 59, no. 1, p. 117-120, DOI:10.1016/j.cirp.2010.03.064.

[10] Mohammadpour, M., Razfar, M.R., Jalili Saffar, R. (2010). Numerical investigating the effect of machining parameters on residual stresses in orthogonal cutting. Simulation Modelling Practice and Theory, vol. 18, no. 3, p. 378-389, DOI:10.1016/j.simpat.2009.12.004.

[11] Dattoma, V., De Giorgi, M., Nobile, R. (2006). On the evolution of welding residual stress after milling and cutting machining. Computers \& Structures, vol. 84, no. 29-30, p. 1965-1976, DOI:10.1016/j. compstruc.2006.08.008.

[12] Outeiro, J.C., Umbrello, D. M'Saoubi, R., (2006). Experimental and numerical modelling of the residual stresses induced in orthogonal cutting of AISI 316L steel. International Journal of Machine Tools and Manufacture, vol. 46, no. 14, p. 1786-1794, DOI:10.1016/j.ijmachtools.2005.11.013.

[13] Rizzuti, S., Umbrello, D., Filice, L., Settineri, L. (2010). Finite element analysis of residual stresses in machining. International Journal of Material Forming, vol. 3, suppl. 1, p. 431-434, DOI:10.1007/s12289-0100799-8.

[14] Bhattacharyya, A. (2008). Predictive Force Modeling of Peripheral Milling. PhD Thesis, University of Florida, Gainesville. 
[15] Gylienè, V., Ostaševičius, V. (2010). FE modeling of orthogonal cutting process, assuming chip segmentation frequency. HSM-8 Conference Proceedings, p. 1-6.

[16] Hallquist, J.O. (1998). LS-DYNA Theoretical Manual. Livermore Software Technology Corporation, Livermore.

[17] Bohdal, Ł., Kukiełka, L. (2006). The effect of selected material parameters on the stress and strain states in the process of cutting a sheet plate with circular cutters. TASK Quarterly, vol. 10, no. 4, p. 391-400.

[18] Gyliene, V., Ostasevicius, V., Sergent, A. (2011). Milling process study, assuming estimation of cutting force. Assembly and Manufacturing (ISAM), 2011 IEEE International Symposium. p. 1-7, DOI:10.1109/ ISAM.2011.5942363.

[19] Koenigsberger, F., Sabberwal, A.J.P., (1961). An investigation into the cutting force pulsations during milling operations. International Journal of Machine Tool Design and Research, vol. 1, no. 1-2, p. 15-33, DOI:10.1016/0020-7357(61)90041-5.

[20] Gyliene, V., Ostasevicius, V. (2011). Cowper-Symonds material deformation law application in material cutting process using LS-DYNA FE code: turning and milling. LS-DYNA ${ }^{\circledR}$ 8th $^{\text {th }}$ European User's conference, p. 1-12.

[21] Hamann, J.C., Grolleau, V., Le Maītre, F. (1996). Machinability improvement of steels at high cutting speeds-study of tool/work material interaction. CIRP
Annals-Manufacturing Technology, vol. 45, no.1, p. 8792, DOI:10.1016/S0007-8506(07)63022-4.

[22] Dey, S., Borvik, T., Hopperstad, O.S., Langseth, M. (2006). On the influence of fracture criterion in projectile impact of steel plates. Computational Materials Science, vol. 38, no. 1, p. 176-191, DOI:10.1016/j.commatsci.2006.02.003.

[23] Abukhshim, N.A., Mativenga, P.T. Sheikh, M.A. (2006). Heat generation and temperature prediction in metal cutting: A review and implications for high speed machining. International Journal of Machine Tools and Manufacture, vol. 46, no. 7-8, p. 782-800, DOI:10.1016/j.ijmachtools.2005.07.024.

[24] Fallbohmer, P., Rodriguez, C.A., Ozel, T., Altan, T. (2000). High-speed machining of cast iron and alloy steels for die and mold manufacturing. Journal Materials Processing Technology, vol. 98, no. 1, p. 104-115, DOI:10.1016/S0924-0136(99)00311-8.

[25] Ostaševičius, O., Gaidys, R., Gylienė, V., Jurènas, V., Daniulaitis, V., Liepinaitis, A. (2011). Passive optimal tool structures for vibration cutting. Journal of Vibroengineering, vol. 13, no. 4, p. 769-777.

[26] Vijay, S.K.S., Pradeep, K.M. (2012). Optimising flow stress input for machining simulations using Taguchi methodology. International Journal of Simulation Modelling, vol. 111, p. 17-28, DOI:10.2507/ IJSIMM11(1)2.195. 